This document is the accepted manuscript version of the following article:

Liu, W., Yang, H., Folberth, C., Müller, C., Ciais, P., Abbaspour, K. C., \& Schulin, R. (2018). Achieving high crop yields with low nitrogen emissions in global agricultural input intensification. Environmental Science and Technology, 52(23), 13782-13791. https://doi.org/10.1021/acs.est.8b03610

\title{
Achieving high crop yields with low nitrogen emissions in global agricultural input intensification
}

Wenfeng Liu ${ }^{1,2,}$, Hong Yang ${ }^{1,3}$, Christian Folberth ${ }^{4}$, Christoph Müller ${ }^{5}$, Philippe Ciais ${ }^{2}$, Karim

C. Abbaspour ${ }^{1}$, Rainer Schulin ${ }^{6}$

${ }^{1}$ Eawag, Swiss Federal Institute of Aquatic Science and Technology, Ueberlandstrasse 133, CH-8600 Duebendorf, Switzerland.

${ }^{2}$ Laboratoire des Sciences du Climat et de l'Environnement, LSCE/IPSL, CEA-CNRS-UVSQ,

Université Paris-Saclay, F-91191 Gif-sur-Yvette, France.

${ }^{3}$ Department of Environmental Sciences, MGU, University of Basel, Petersplatz 1, CH-4003

Basel, Switzerland.

${ }^{4}$ Ecosystem Services and Management Program, International Institute for Applied Systems

Analysis (IIASA), Schlossplatz 1, A-2361 Laxenburg, Austria.

${ }^{5}$ Potsdam Institute for Climate Impact Research, 14473 Potsdam, Germany.

${ }^{6}$ ETH Zürich, Institute of Terrestrial Ecosystems, Universitätstr. 16, CH-8092 Zürich, Switzerland.

*Corresponding author. Email: wenfeng.liu@eawag.ch \& wfliu2012@gmail.com 


\section{Abstract}

2 Increasing demand for food is driving a worldwide trend of agricultural input intensification.

3 However, there is no comprehensive knowledge about the interrelations between potential yield

4 gains and environmental trade-offs that would enable the identification of regions where

5 input-driven intensification could achieve higher yields, yet with minimal environmental impacts. We explore ways of enhancing global yields, while avoiding significant nitrogen $(\mathrm{N})$

7 emissions $\left(\mathrm{N}_{\mathrm{e}}\right)$ by exploring a range of $\mathrm{N}$ and irrigation management scenarios. The simulated

8 responses of yields and $\mathrm{N}_{\mathrm{e}}$ to increased $\mathrm{N}$ inputs $\left(\mathrm{N}_{\mathrm{in}}\right)$ and irrigation show high spatial

9 variations due to differences in current agricultural inputs and agro-climatic conditions.

10 Nitrogen use efficiency (NUE) of yield gains is negatively correlated with incremental $\mathrm{N}_{\mathrm{e}}$ due

11 to $\mathrm{N}_{\text {in }}$ additions. Avoiding further intensification in regions where high fractions of climatic

12 yield potentials, $\geq 80 \%$, are already achieved is key to maintain good NUE. Depending on the

13 intensification scenarios, relative increases in $\mathrm{N}_{\mathrm{e}}$ could be reduced by $0.3-29.6 \%$ of the baseline

$14 \mathrm{~N}_{\mathrm{e}}$ with this intensification strategy as compared to indiscriminate further intensification, at the

15 cost of a loss of yield increases by $0.2-16.7 \%$ of the baseline yields. In addition, irrigation water

16 requirements and $\mathrm{N}_{\text {in }}$ would dramatically decrease by considering this intensification strategy.

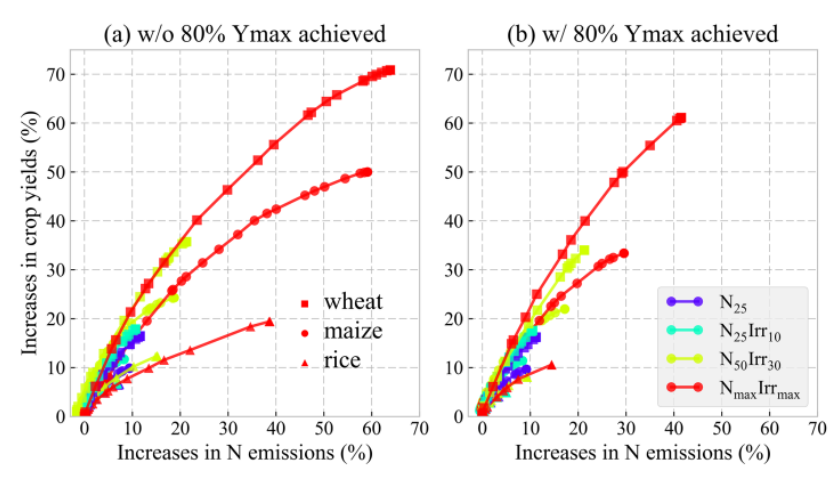

TOC Art 


\section{Introduction}

With a continuously growing global population, shifts to more animal-based diets, and possibly increasing competition in agricultural land use between food and biofuel crops, food production has to increase substantially ${ }^{1-3}$. It was estimated that global food production needs to be doubled by 2050 if no changes occur on the demand side ${ }^{4}$. There are in principle two different strategies to increasing food production: expansion of croplands and intensification ${ }^{5}$. For the first option, however, suitable land resources are very limited and their conversion to cropland is increasingly constrained by other land-use purposes. In many places, croplands are actually shrinking due to encroachment by urban development ${ }^{6,7}$. The option of cropland expansion is only feasible in underdeveloped areas and often at high environmental and climate change costs such as greenhouse gas emissions and biodiversity loss from forest clearing ${ }^{8}$. For the majority of countries and regions, intensification of crop production on existing croplands is the only way to meet the increasing food demand. Concerning limited resources and severe environmental impacts, modern agriculture is facing tremendous challenges ${ }^{9}$. A major task faced by scientists, farmers, and policy makers is to find ways to increase global food production while keeping the environmental costs at a tolerable level ${ }^{10-13}$.

Since the Green Revolution in the 1960s, crop yields have been increased, in particular through the breeding of more productive crop varieties ${ }^{14}$ and the intensification of land management with increasing fertilizer inputs and irrigation ${ }^{15}$. However, input intensification has also put substantial pressure on the environment due to unbalanced input-output agricultural systems. The mismatch between inputs and outputs not only decreased resource use efficiency ${ }^{16-19}$, but 
also caused serious environmental problems ${ }^{20-24}$. In particular, increasing inputs of nitrogen $(\mathrm{N})$ fertilizers have led to high $\mathrm{N}$ emissions to the environment ${ }^{25,26}$, causing severe eutrophication and drinking water quality deterioration ${ }^{27}$, as well as air pollution by $\mathrm{N}_{2} \mathrm{O}$ and $\mathrm{NH}_{3}$ emissions ${ }^{28}$. Hence, there is an ever more pressing need to develop pathways towards input intensification without further compromising environmental health and quality $4,11,29,30$.

Given that the yields of major crops have recently been stagnated or even decreased in many regions of the world, where high agricultural inputs were applied ${ }^{31-34}$, it seems that the benefits of additional inputs, particularly fertilizers, are saturating in these regions, suggesting that further input intensification will not help to increase yields. However, the scope for improved efficiency varies among different cropping systems ${ }^{35}$. It is essential to identify regions where a high yield return can still be obtained at low environmental impacts and to explore how input intensification can be achieved in these regions most efficiently. Previous studies have shown a high potential to further increase crop production through agricultural intensification, and concluded that this is key to increasing global food production to meet the demand ${ }^{36-41}$. However, these studies have been limited in several aspects, including: a) focusing on one type of input only, either $\mathrm{N}^{37}$ or irrigation ${ }^{36}$; b) no explicit consideration of environmental impacts $^{39,40}$; and c) simply using $\mathrm{N}$ surpluses to indicate environmental impacts of $\mathrm{N}$ pollution without explicitly quantifying different forms of $\mathrm{N}$ emissions ${ }^{41}$.

Here we comprehensively address the agricultural challenges elaborated above by using the global agronomic model PEPIC ${ }^{42}$, Python-based Environmental Policy Integrated Climate (EPIC), to explore the benefits and trade-offs of further global agricultural input intensification 
in terms of increased crop yields and associated $\mathrm{N}$ emissions $\left(\mathrm{N}_{\mathrm{e}}\right)$. We used food production units (FPUs) as a spatial unit. The FPUs are based on river basins and economic regions as introduced by Cai and Rosegrant ${ }^{43}$ and modified by Kummu et al. ${ }^{44}$ Focusing on $\mathrm{N}$ inputs $\left(\mathrm{N}_{\text {in }}\right)$ and irrigation water (Irr), we considered four input intensification scenarios representing low, high and max levels of intensification (two scenarios for the low level) in addition to a baseline scenario with no additional intensification. Three major cereal crops (maize, rice, and wheat) were included in the analysis. In addition to looking into the differences in yields $(\Delta \mathrm{Y})$, differences in $\mathrm{N}_{\mathrm{e}}\left(\Delta \mathrm{N}_{\mathrm{e}}\right)$, and differences in input requirements $\left(\Delta \mathrm{N}_{\mathrm{in}}\right.$ and $\left.\Delta \mathrm{Irr}\right)$ between the intensification and the baseline scenarios, we explored the relationships between $\Delta \mathrm{Y}$ and $\Delta \mathrm{N}_{\mathrm{e}}$ in response to $\Delta \mathrm{N}_{\text {in }}$ to identify the priority regions for intensification. We also assessed the $\mathrm{N}$ use efficiency (NUE) of yield gains as $\Delta \mathrm{Y} / \Delta \mathrm{N}_{\text {in }}$ and $\mathrm{N}$ emission intensity of new inputs as

$72 \Delta \mathrm{N}_{\mathrm{e}} / \Delta \mathrm{N}_{\mathrm{in}}$.

\section{Materials and methods}

\subsection{Simulation model and input data}

The PEPIC model ${ }^{42}$ was used to simulate crop growth at a daily time step and the associated nutrient dynamics globally at a spatial resolution of 30 arc minutes (about $50 \mathrm{~km}$ at the equator). PEPIC has been used for investigating global crop-water relations of maize ${ }^{42}$ and assessing

78 global $\mathrm{N}$ and phosphorus $(\mathrm{P})$ emissions from the cultivation of major crops ${ }^{12,26}$. In addition, it

79 also shows comparable performance in representing yield variability at country level along with 13 other global crop models participating in the Agricultural Model Intercomparison and

81 Improvement Project (AgMIP) ${ }^{45,46}$. Inputs for PEPIC include longitude, latitude, elevation, 
slope, soil properties (e.g. layer depth, $\mathrm{pH}$, bulk density, organic carbon content), climate data (precipitation, temperature, solar radiation, relative humidity, wind speed), land cover, and crop management information. Land cover data are derived from the MIRCA2000 datasets, which provide rainfed and irrigated cultivation areas for $26 \mathrm{crops}^{47}$. As for management data, planting date, harvesting date, fertilizer, and irrigation are required. Planting and harvesting dates were obtained from the Center for Sustainability and the Global Environment (SAGE) ${ }^{48}$. Crop-specific fertilizer and manure application data for the baseline simulation (including $\mathrm{N}$ and P) were downloaded from the EarthStat dataset (http://www.earthstat.org/), which were based on Mueller et al. ${ }^{49}$ and West et al. ${ }^{50}$ Information on model performance and other input data is provided in the Supporting Information.

\subsection{Management practices and intensification scenarios}

In this study, we considered four intensification scenarios- $\mathrm{N}_{25}, \mathrm{~N}_{25} \operatorname{Irr}_{10}, \mathrm{~N}_{50} \operatorname{Irr}_{30}$ and $\mathrm{N}_{\max } \mathrm{Irr}_{\max }$ - in addition to the baseline scenario (Table 1). A sufficient amount of $\mathrm{P}$ was applied automatically in each scenario to eliminate the effects of P deficit on plant growth following Folberth et al. ${ }^{51} \mathrm{~N}_{\text {in }}$ in the baseline $\left(\mathrm{N}_{\text {in-base }}\right)$ was determined by the minimum value between actual $\mathrm{N}_{\text {in }}\left(\mathrm{N}_{\text {in-a }}\right)$ and automatic $\mathrm{N}_{\text {in }}\left(\mathrm{N}_{\text {in-auto }}\right)$, where $\mathrm{N}$ application is based on crop $\mathrm{N}$ requirements, for the baseline yield simulation. Here, $\mathrm{N}_{\text {in-a }}$ was based on the EarthStat dataset, while $\mathrm{N}_{\text {in-auto }}$ was estimated by PEPIC with automatic $\mathrm{N}$ fertilization without $\mathrm{N}$ limitation at a trigger value of $10 \% \mathrm{~N}$ stress ${ }^{52}$ under the baseline irrigation cropland condition based on the MIRCA2000 dataset. Such setting excluded the impacts of over $\mathrm{N}$ application on $\mathrm{N}_{\mathrm{e}}$ in some regions ${ }^{26,53}$, since this study focused on the effects of input additions. The automatic $\mathrm{N}$ 
fertilization used here can determine the proper amount of $\mathrm{N}_{\text {in }}$ at right time based on soil $\mathrm{N}$ concentration and crop $\mathrm{N}$ requirements ${ }^{54}$. It deserves to note that the automatic $\mathrm{N}$ fertilization may lead to optimistic bias on NUE simulated and that actual management practices are often less targeted (e.g. timing). Irrigation was applied automatically without water limitation for the irrigated cultivation at a trigger value of $10 \%$ water stress ${ }^{55}$. Increased $\mathrm{N}_{\text {in }}$ and conversion of rainfed to irrigated cropland relative to the baseline were considered as intensification scenarios in this study. For $\mathrm{N}_{\text {in }}$, we first used PEPIC to determine the maximum $\mathrm{N}_{\text {in }}\left(\mathrm{N}_{\text {in-max }}\right)$ by using the automatic fertilization schedule setting different $\mathrm{N}_{\text {in }}$ caps considering all croplands with full irrigation. We found that when $\mathrm{N}_{\mathrm{in}}$ cap was set to $400 \mathrm{~kg} \mathrm{~N}$ per ha, maximum crop yields (Ymax) could be achieved for the three crops (Table S1). Therefore, actual $\mathrm{N}_{\text {in }}$ estimated from this condition was used as maximum $\mathrm{N}_{\mathrm{in}}$. Here, Ymax was estimated by forcing the model with sufficient water and $\mathrm{N}$ fertilizer without changing the response curves of yields to $\mathrm{N}$ and water. This definition of Ymax is consistent with Lassaletta et al. ${ }^{18,56}$, Mueller et al. ${ }^{57}$, and Mogollón et al. ${ }^{58}$, but different from the definition of van Ittersum et al. ${ }^{59}$, that also considered changes in the response curves. Combination of this fertilizer and full irrigation was applied in the $\mathrm{N}_{\max } \operatorname{Irr}_{\max }$ scenario. Then, the difference between $\mathrm{N}_{\text {in-max }}$ and $\mathrm{N}_{\text {in-base, }}$, i.e. $\Delta \mathrm{N}_{\text {in-max }}$, was calculated for each grid cell.

In $\mathrm{N}_{25}, \mathrm{~N}_{\text {in }}$ was increased by $25 \%$ of $\Delta \mathrm{N}_{\text {in-max }}$ relative to the baseline, while in $\mathrm{N}_{25} \operatorname{Irr}_{10}, 10 \%$ of the rainfed cropland was converted to irrigated land in addition to a $25 \%$ of $\Delta \mathrm{N}_{\mathrm{in}-\mathrm{max}}$ increase in $\mathrm{N}_{\text {in. }}$ In $\mathrm{N}_{50} \mathrm{Irr}_{30}, 30 \%$ of the rainfed land was converted to irrigated land in addition to a $50 \%$ of 
$\Delta \mathrm{N}_{\text {in-max }}$ increase in $\mathrm{N}_{\text {in }}$. These levels of intensification were based on Mueller et al. ${ }^{41}$, who found that jointly increasing $\mathrm{N}_{\text {in }}$ by $30 \%$ and irrigated lands by $25 \%$ would reach productivity levels that represent $75 \%$ of the attainable yields of the year 2000 . Therefore, we considered an increasing intensification level with an ascending order of baseline, $\mathrm{N}_{25}, \mathrm{~N}_{25} \operatorname{Irr}_{10}, \mathrm{~N}_{50} \operatorname{Irr}_{30}$, and $\mathrm{N}_{\max } \operatorname{Irr}_{\max }$. Although global constant percentage values of $\Delta \mathrm{N}_{\text {in-max }}$ and rainfed land were used here to increase $\mathrm{N}_{\text {in }}$ and irrigation, the actual increases in $\mathrm{N}_{\text {in }}$ and irrigation were different due to the large differences in $\mathrm{N}_{\text {in }}$ and rainfed land area under the baseline condition (Figs. S1 and S2) and the input requirements under the $\mathrm{N}_{\max } \operatorname{Irr}_{\max }$ scenario. It should be noted that it may not be practical to set the high- and/or max-level input intensification scenarios everywhere across the world. This holds particularly for many poor countries in Africa, as they are currently in lack of infrastructure and/or enough water and fertilizer to reach such intensified agricultural input requirements. However, the scenarios considered here reflect general mechanisms and challenges under the agricultural intensification. Thus, they provide useful information on exploring sustainable pathways towards future agricultural development. They can also be used in land use socio-economic models to prioritize agricultural subsidies and better agricultural practices for increasing $\mathrm{N}_{\text {in }}$ or $\mathrm{N}$ recycling in regions where yields are severely limited by this nutrient.

\subsection{Definition of target variables and data analysis}

Four model outputs were considered in the analysis, i.e. irrigation water (Irr [mm]), N inputs $\left(\mathrm{N}_{\text {in }}\left[\mathrm{kg} \mathrm{N}\right.\right.$ per ha]), yields ( $\mathrm{Y}$ [t per ha]), and $\mathrm{N}$ emissions $\left(\mathrm{N}_{\mathrm{e}}\left[\mathrm{kg} \mathrm{N}\right.\right.$ per ha]). In this study, $\mathrm{N}_{\mathrm{e}}$ refers to total $\mathrm{N}$ emissions, including $\mathrm{N}$ emissions to the aquatic and atmospheric environments, 

rainfed and irrigated conditions. Therefore, there are two response curves of yields and $\mathrm{N}_{\mathrm{e}}$ to

$147 \mathrm{~N}_{\text {in }}$ for irrigated and rainfed cultivations. The combined outputs of each variable were 148 calculated using the area-weighted average of irrigated and rainfed outputs based on the 149 MIRCA2000 dataset of crop-specific fractions of irrigated and rainfed land for each crop in each grid cell ${ }^{47}$. The combined results were aggregated to FPUs, continental, and global levels.

151 Subsequently, the differences of each variable between the intensification scenarios and the 152 baseline were calculated, i.e. differences in $\operatorname{Irr}(\Delta \operatorname{Irr})$, differences in $\mathrm{N}_{\text {in }}\left(\Delta \mathrm{N}_{\text {in }}\right)$, differences in $\mathrm{Y}$ $153(\Delta \mathrm{Y})$, and differences in $\mathrm{N}_{\mathrm{e}}\left(\Delta \mathrm{N}_{\mathrm{e}}\right)$. For FPUs with $\Delta \mathrm{Y}<0.05 \mathrm{t}$ per ha, outputs under the 154 intensification scenarios were treated as the same values of the baseline to exclude possible 155 errors due to minor responses. After this treatment, $\Delta \mathrm{Irr}, \Delta \mathrm{N}_{\mathrm{in}}, \Delta \mathrm{Y}$, and $\Delta \mathrm{N}_{\mathrm{e}}$ were re-evaluated. 156 The NUE of yield gains, defined as ratio $\Delta \mathrm{Y} / \Delta \mathrm{N}_{\mathrm{in}}$, and $\mathrm{N}$ emission intensity of new inputs, 157 defined as ratio $\Delta \mathrm{N}_{\mathrm{e}} / \Delta \mathrm{N}_{\mathrm{in}}$, were calculated to explore the responses of yields and $\mathrm{N}_{\mathrm{e}}$ to $\mathrm{N}_{\text {in }}$ 158 additions under different intensification scenarios.

159 We constructed frontier lines of cumulative $\Delta \mathrm{Y}$ to cumulative $\Delta \mathrm{N}_{\mathrm{e}}$ by intensifying the FPUs one 160 by one. We first focused on the FPUs with low $\mathrm{N}$ emission intensity of new inputs and high 161 NUE of yield gains and then on the FPUs with high N emission intensity of new inputs and low 162 NUE of yield gains. It means that we logically intensified the FPUs with an ascending order of $163 \mathrm{~N}$ emission intensity of new inputs and a descending order of NUE of yield gains. In addition to 164 intensifying all FPUs to high/max levels, we investigated the impacts of stopping 165 intensification in FPUs where a target yield, defined by a given fraction of Ymax, is achieved. 
Different fractions $(70 \%, 75 \%, 80 \%, 85 \%, 90 \%$, and $95 \%)$ of Ymax were tested. If a given

167 yield target was already achieved in an FPU under scenarios of baseline, $\mathrm{N}_{25}, \mathrm{~N}_{25} \operatorname{Irr}_{10}, \mathrm{~N}_{50} \operatorname{Irr}_{30}$

168 scenarios, we stopped further intensification in that FPU.

\section{3. Results}

\subsection{Yield benefits}

171

The simulated responses of crop yields to increased $\mathrm{N}_{\mathrm{in}}$ and irrigation showed high spatial

172 variations, with very large effects in some regions, but only minor ones in other areas, mainly

173 reflecting current limitations (Fig. 1). These benefits also showed different spatial patterns

174 among the three crops. Areas with high $\Delta \mathrm{Y}$ for maize and rice were found to be concentrated mainly in the southern parts of Africa and South America, where the baseline yields were quite

176 low and differences in yields between the $\mathrm{N}_{\max } \operatorname{Irr}_{\max }$ and baseline scenarios were very high (Fig.

177 S3). In addition to these regions, parts of East Europe and the Middle East also showed large

$178 \Delta \mathrm{Y}$ for wheat. Wheat presented smaller yield improvements compared to maize and rice. For

179 other regions, particularly China and India, only small $\Delta \mathrm{Y}$ were predicted for the three crops.

180 Globally, the average $\Delta \mathrm{Y}$ in the four intensification scenarios ranged between 10 and $50 \%$ of

181 baseline yields for maize, 7 and 19\% for rice, and 16 and $71 \%$ for wheat (Table 2). Yields

182 responded mainly to increased $\mathrm{N}_{\mathrm{in}}$ and less to intensified irrigation. Increased $\mathrm{N}_{\text {in }}$ were found to

183 substantially increase irrigation water use efficiency (defined as yield per unit of applied

184 irrigation water), while the effects of irrigation additions on NUE (defined as yield per unit of 185 applied $\mathrm{N}_{\text {in }}$ ) were quite small at the continental level (Tables S2 and S3). Meanwhile, to achieve 186 high yields, significant increases in the inputs of these resources were required (Table 2), with 
$\Delta \operatorname{Irr}$ between 0 and $250 \%$ of baseline irrigation water and $\Delta \mathrm{N}_{\text {in }}$ between 12 and $138 \%$ of baseline $\mathrm{N}_{\mathrm{in}}$, depending on scenarios and crops.

Insert Fig. 1 here

Insert Table 2 here

\subsection{Nitrogen emissions}

The simulations predicted that yield benefits from $\mathrm{N}_{\text {in }}$ and irrigation intensification would result in substantial $\Delta \mathrm{N}_{\mathrm{e}}$ around the world, with increases varying between 9 and $59 \%$ of the baseline $\mathrm{N}_{\mathrm{e}}$ for maize, 7 and 39\% for rice, and from 12 to $64 \%$ for wheat among the four scenarios (Table 2). Increases in $\mathrm{N}_{\mathrm{e}}$ was particularly high in Africa, Oceania, and South America for maize and rice, and in Africa, Europe, Oceania, and South America for wheat (Fig. 2 and Fig. S4). The overall geographical distribution patterns were similar to those for the respective $\Delta \mathrm{Y}$, but there were also some differences. Large $\Delta \mathrm{N}_{\mathrm{e}}$ were predicted in Southeast Asia for all three crops and in the eastern parts of the USA for wheat, while yields were not expected to increase significantly in these regions in response to $\mathrm{N}_{\text {in }}$ and irrigation additions. While increasing $\mathrm{N}_{\text {in }}$ always increased $\mathrm{N}_{e}$, increased irrigation could reduce $\mathrm{N}_{e}$ in some regions relative to the baseline scenario. That is because the plants that grow better under irrigation cultivation take up more $\mathrm{N}$.

Insert Fig. 2 here

\subsection{Relationship between yield increases and nitrogen emissions}

The NUE of yield gains, expressed in terms of the ratio $\Delta \mathrm{Y} / \Delta \mathrm{N}_{\mathrm{in}}$, and the $\mathrm{N}$ emission intensity of new inputs, expressed as the ratio $\Delta \mathrm{N}_{\mathrm{e}} / \Delta \mathrm{N}_{\mathrm{in}}$, present opposite spatial distribution patterns at 
the FPUs level (Figs. S5 and S6). The Southeast Asia and the northern parts of South America showed high $\mathrm{N}$ emission intensity of new inputs for maize and rice. The NUE of yield gains showed clear negative linear relationships to the $\mathrm{N}$ emission intensity of new inputs for all the three crops, especially for maize and rice under all four intensification scenarios, and for wheat under the $\mathrm{N}_{\max } \operatorname{Irr}_{\max }$ scenario (Fig. 3). The position of individual FPU along the relationships between NUE of yield gains and $\mathrm{N}$ emission intensity of new inputs was closely related to the magnitude of $\mathrm{N}_{\text {in }}$ additions. In contrast, the increases in irrigation land had little effect on the balance between relative benefits on yield vs. $\mathrm{N}_{\mathrm{e}}$, as these relationships showed little differences between the scenarios without and with irrigation addition, for instance between

$217 \mathrm{~N}_{25}$ and $\mathrm{N}_{25} \operatorname{Irr}_{10}$. The negative relationships shown in Fig. 3 indicate that there is a win-win 218 situation with higher yields and low $\mathrm{N}_{\mathrm{e}}$ if further input intensification concentrates on regions 219 where additional inputs have the highest NUE of yield gains, as these are also the regions with the smallest additional $\mathrm{N}_{\mathrm{e}}$.

222 In most FPUs with a high N emission intensify of new inputs and a low NUE of yield gains 223 (Figs. S5 and S6), yields under each intensification scenario have already obtained a high 224 fraction (e.g. 80\%) of Ymax under the former scenario considering an order of baseline, $\mathrm{N}_{25}$, $225 \mathrm{~N}_{25} \operatorname{Irr}_{10}, \mathrm{~N}_{50} \operatorname{Irr}_{30}$ and $\mathrm{N}_{\max } \operatorname{Irr}_{\max }$ (Fig. 3). This means that significant $\mathrm{N}_{\mathrm{e}}$ can be avoided by 226 stopping further increases in $\mathrm{N}_{\text {in }}$ and irrigation applications in such FPUs. This condition was 227 found to be especially common for rice cultivation, where about $79 \%$ of the croplands presently under rice cultivation already reaches $80 \%$ of Ymax in the baseline scenario (Table S4). For 
wheat and maize, the respective percentages were $35 \%$ and $26 \%$. The regions showing low yield gap were mainly located in East Asia, central Europe and the eastern USA for maize, eastern and southeastern Asia for rice, and China and India for wheat (Fig. S7). In the $\mathrm{N}_{50} \operatorname{Irr}_{30}$ scenario, the fraction of croplands cannot achieve $80 \%$ of the Ymax is still big for maize and wheat.

\subsection{Frontier lines for intensifying croplands on a global scale}

Based on the negative relationship between NUE of yield gains and $\mathrm{N}$ emission intensity of new inputs as shown in Fig. 3, we constructed the distributions of cumulative $\Delta \mathrm{Y}$ against cumulative $\Delta \mathrm{N}_{\mathrm{e}}$ (Fig. 4), sorting the FPUs by an ascending order in $\mathrm{N}$ emission intensity of new inputs and meanwhile a descending order in NUE of yield gains. Starting with FPUs low in $\Delta \mathrm{N}_{\mathrm{e}}$ and high in $\Delta \mathrm{Y}$ which are the best regions for intensification, these lines decrease in slope as $\Delta \mathrm{Y}$ decreases, while $\Delta \mathrm{N}_{\mathrm{e}}$ increases. This is particularly notable for scenarios $\mathrm{N}_{50} \operatorname{Irr}_{30}$ and $\mathrm{N}_{\max } \operatorname{Irr}_{\max }$.

241 We observed that initial increases in yields can be achieved by lower-input systems at less environmental burden (e.g. yellow line steeper than red line for rice and initially for wheat and maize). Furthermore, the frontier lines show a large difference between the $\mathrm{N}_{\max } \operatorname{Irr}_{\max }$ and the

244 other scenarios, indicating the high $\mathrm{N}$ pollution versus small yield benefits of further intensifying crop production when the level of intensification is already high.

247 An important strategy for limiting $\Delta \mathrm{N}_{\mathrm{e}}$ with minimal compromises on yield increases is to 248 avoid further intensification in FPUs, where high fractions of Ymax have been achieved, which 249 we here define as a threshold of $80 \%$ (Fig. 4). With this condition, simulated $\Delta \mathrm{N}_{\mathrm{e}}$ were reduced 
251 the baseline $\mathrm{N}_{\mathrm{e}}$ ) for maize; from $5.4-28.7 \mathrm{~kg} \mathrm{~N}$ per ha to $3.7-10.7 \mathrm{~kg} \mathrm{~N}$ per ha (the reduction 252 representing $2.2-24.3 \%$ of the baseline $\mathrm{N}_{\mathrm{e}}$ ) for rice; and from $5.1-27.7 \mathrm{~kg} \mathrm{~N}$ per ha to $4.9-18.1$ $\mathrm{kg} \mathrm{N}$ per ha (the reduction representing $0.4-22.3 \%$ of the baseline $\mathrm{N}_{\mathrm{e}}$ ) for wheat, depending on the scenarios. Expected $\Delta \mathrm{Y}$ were reduced by only $0.0-0.9 \mathrm{t}$ per ha (corresponding to $0.2-16.7 \%$ of the baseline yields) for maize; $0.1-0.4 \mathrm{t}$ per ha (corresponding to $1.8-8.8 \%$ of the baseline yields) for rice; and $0.0-0.3 \mathrm{t}$ per ha (corresponding to $0.2-9.8 \%$ of the baseline yields) for wheat (Tables 2 and 3). Furthermore, the results also show that much less $\mathrm{N}$ and irrigation water resources are required to achieve the same increases in yield with a strategy in which further intensification is limited to cropland where the yield gap is still comparatively large than with indiscriminate further intensification. In addition to restricting intensification to FPUs with yield levels of $<80 \%$ Ymax, we performed the analogous analysis setting the restriction fractions at $70 \%, 75 \%, 85 \%, 90 \%$, and $95 \%$ of $Y \max$ (Fig. S8). Similar trends for $\Delta \mathrm{Y}$ and $\Delta \mathrm{N}_{\mathrm{e}}$ were found for these fractions as with the fraction of $80 \%$. However, the trade-offs between $\mathrm{Y}$ achievements and increases in $\mathrm{N}_{\mathrm{e}}$ varied by using the different yield target levels.

\section{Discussion}

267 To detail the different responses of yields and $\mathrm{N}_{\mathrm{e}}$ to $\mathrm{N}_{\text {in }}$ and water additions, the response curves 268 of yields and $\mathrm{N}_{\mathrm{e}}$ to $\mathrm{N}_{\mathrm{in}}$ under irrigated and rainfed cultivations are displayed for eight continental-climate regions in Fig. 5. The climate classification is based on the Köppen-Geiger climate map ${ }^{60}$. We observed very different responses in different regions, consistent with the 
271 EPIC simulations from Balkovič et al. ${ }^{61}$ The differences between the irrigated and rainfed 272 cultivations are particularly high in the arid regions, where the irrigation water requirements are 273 generally high. These response curves from PEPIC highlight the large spatial variability of 274 yield benefits and $\mathrm{N}_{\mathrm{e}}$ trade-offs under intensification scenarios on a global scale. Comparison of 275 the PEPIC response curves with those from other crop models would help to estimate the uncertainty on our results arising from the use of a single model.

The high spatial heterogeneity of the responses of yields and $\mathrm{N}_{\mathrm{e}}$ to increased $\mathrm{N}_{\mathrm{in}}$ and irrigation 279 inputs is mainly explained by differences in these inputs between under the baseline scenario and under the $\mathrm{N}_{\max } \operatorname{Irr}_{\max }$ scenario. Regions with a high level of baseline $\mathrm{N}_{\text {in }}$ (Fig. S1) generally 281 respond with low NUE of yield gains but high $\mathrm{N}$ emission intensity of new inputs to further intensification. This is in agreement with previous studies. When $\mathrm{N}_{\text {in }}$ is already high, the yield benefits of additional $\mathrm{N}_{\mathrm{in}}$ are low ${ }^{18}$, while the potential of $\mathrm{N}_{\mathrm{e}}$ tends to be high ${ }^{14}$. Maximum $\mathrm{N}$ requirements for achieving Ymax presented high variation (Fig. S1) and were mainly 285 determined by climate condition, particularly the potential heat units (Fig. S9), as both of them show quite similar spatial distribution. Such patterns of maximum $\mathrm{N}_{\text {in }}$ also partially explain the heterogeneity of yield responses to $\mathrm{N}_{\mathrm{in}}$. Compared to $\mathrm{N}_{\mathrm{in}}$, most regions showed relatively low

$288 \Delta \mathrm{Y}$ in response to more irrigation in all three crops, with significant variations across regions

289 (Fig. S10), which is true as most cultivation regions of these three crops were not found limited 290 by irrigation ${ }^{49}$. Especially, yield response is more sensitive to $\mathrm{N}_{\text {in }}$ additions than to irrigation in 291 Africa and South America, where the baseline $\mathrm{N}_{\text {in }}$ was generally very low. The different 
responses of yields to irrigation additions are mainly due to different fractions of irrigated lands to total cultivated lands (Fig. S2) and the differences in irrigation requirements under different scenarios, e.g. the baseline management as shown in Fig. S11. A low irrigation requirement indicates that growing season precipitation is generally sufficient for crop growth (Fig. S12), and so there are low benefits from increased irrigation. On the other hand, there is only limited opportunity to further increasing yields by taking additional land under irrigation where a large

298 fraction of the cropland is already under irrigation. On land where yields are already close to 299 what can be achieved with the maximum $\mathrm{N}$ and irrigation water inputs, further increasing the intensity can produce only minor benefits, while the environmental impacts and the consumption of resources become more significant. Such regions need to be identified and excluded from further intensification.

Based on our simulations, it was not possible to double the production of the three crops on the current cropland area even if there was no limit on $\mathrm{N}$ fertilizer application and irrigation, especially in rice production (Table 2). Similar findings were reported by Mueller et al. ${ }^{49}$, who estimated production potentials close to $100 \%$ of maximum attainable yields through nutrients and irrigation management. Therefore, other measures need to be considered to further increase yields, such as breeding more productive varieties ${ }^{62}$, change of cropping intensities ${ }^{63}$, and better

309 allocation on a global scale of crops to cultivated land ${ }^{40}$, among others. Combining these 310 measures with better $\mathrm{N}$ and irrigation management can be expected to further increase Ymax 311 and strengthen the responses of yields to $\mathrm{N}_{\text {in }}$ and irrigation in currently high yield regions, as 
which focuses on reducing external inputs, could also be considered in the already intensified regions to alleviate environmental impacts with minor yield reduction ${ }^{64}$. Nevertheless, here we focused on the three major food crops. It is worth noting that other types of crops (particularly fruits and vegetable) may hold the potential to double the production ${ }^{65}$. For instance, apple 317 yields in China could increase from $16.5 \mathrm{t}$ per ha to $37 \mathrm{t}$ per ha through better management ${ }^{66}$. Hence, a comprehensive assessment including different management options and incorporating more crops should be conducted in further research. significant environmental impacts. While there is sufficient $\mathrm{N}$ in the atmosphere for practically unlimited industrial production of mineral $\mathrm{N}$ fertilizer, the energy required for it is likely to set an upper limit. Already about $2 \%$ of the world's energy use is for the production of reactive $\mathrm{N}^{67}$. Moreover, there is still a long way to go for many developing countries, mainly in Africa, to afford and distribute enough nutrients for their croplands. In comparison to $\mathrm{N}$ fertilizer, 326 freshwater is a much more limited resource ${ }^{68}$ and its spatiotemporal distribution is already very 327 uneven for natural reasons ${ }^{69}$. That is why we set lower levels of irrigated land expansion. While 328 we found that by expanding the irrigated areas, maize and wheat yields could be increased 329 substantially in the western USA and western and central Asia (Fig. S10), the available water 330 resources there set a rather low upper limit to this option ${ }^{70}$. Further expansion of irrigation 331 agriculture hence bears the risk of worsening this problem. Therefore, it will be vital to increase 332 the efficiency of irrigation ${ }^{71,72}$ and fertilizer ${ }^{19}$ applications. As shown here, one strategy to 333 achieve this is to concentrate intensification efforts in regions with currently low yields and 
high yield potentials, while avoiding further intensification in regions where yields are already very high. This strategy could simultaneously conserve agricultural resources and also substantially reduce additional $\mathrm{N}$ pollution.

Mueller et al. ${ }^{41}$ also explored trade-offs between excess $\mathrm{N}$ (differences between $\mathrm{N}_{\text {in }}$ and $\mathrm{N}$ in crop harvest) and crop production using frontier lines. The difference between our results and their study is that we used frontier lines to explore the benefits of avoiding further 'useless' 340 intensification in regions where yields are already close to their maximum levels, i.e. $70-95 \%$ 341 of Ymax (Fig. 4 and Fig. S8). The $\Delta \mathrm{N}_{\mathrm{e}}$ may be reduced if setting a low yield target. But then the increases in yields will also be lower. Thus, it is important to find a level at which these effects are in a desirable balance. However, setting such a target level is subject to local and regional

344 policies, social and economic trade-offs, access to $\mathrm{N}$ fertilizers, capacity to improve 345 agronomical practices, as well as consideration of regional environmental vulnerabilities. Due 346 to significant variations of agricultural performance among different countries in terms of 347 trade-offs between yield achievements and environmental impacts because of different natural 348 conditions (e.g. climate and soil) and agronomic practices (e.g. different NUE), much more 349 efforts should be made to determine a reasonable yield target level on local scale ${ }^{57,73}$. Due to 350 enormous disparities in capacity and socioeconomic conditions among different countries, it 351 may not be possible to intensify agricultural inputs to such a reasonable yield target level in the 352 short term in economically week regions, e.g. many poor countries in Africa. Therefore, in 353 addition to setting a critical target level, it is also important to make sure that the high yield 354 improvements without significant environmental costs could be practically achieved for these 
regions. Answering this question requires detailed socio-economic information and complex economic models to address benefits and trade-offs between agricultural intensification and

357 food trade-dependence ${ }^{53,73}$. This is beyond the focus of the current study, but it certainly

358 deserves an in-depth investigation.

359 Our previous analysis showed that the PEPIC model realistically captured large-scale $\mathrm{N}_{\mathrm{e}}$ due to

$\mathrm{N}$ inputs, but with high uncertainties from model parameters ${ }^{26}$. In this study, we document the

361 variable responses of yields and $\mathrm{N}_{\mathrm{e}}$ to $\mathrm{N}_{\mathrm{in}}$ and water additions in different regions across the world. More detailed follow up studies to significantly reduce uncertainties should focus on evaluating the PEPIC response against data from field experiments with nutrient and water treatments $^{7475}$, and on comparing PEPIC response curves with other crop models, such as planned in $\operatorname{AgMIP}^{76}$. We did not consider the impacts of climate change and adaptation strategies $^{77}$, which are also important factors affecting future food security, although their 367 uncertainties are also high ${ }^{55,78,79}$. As the purpose of this study is to investigate the yield potentials of input intensification, associated environmental trade-offs, and their regional

369 differences, we only considered four intensification scenarios (representing low, high, and 370 maximum levels) in order to reduce the computation time. A full range of $\mathrm{N}$ and irrigation 371 intensification scenarios would help to identify the optimal intensification level. Overcoming 372 the limitations specified above was beyond the scope of this study and will be subject to future 373 research.

374 Supporting Information: Details on model description and model performance. Details on 375 nitrogen inputs, crop yield responses, nitrogen emission responses, and percentage of potential 
yields achieved under difference scenarios. Details on irrigated land, potential heat units,

377 irrigation water requirements, and growing season precipitation under baseline. Details on 378 yield-nitrogen responses, water use efficiency, nitrogen use efficiency at the continental level.

379 Author contributions: W.L. and H.Y. designed research. W.L. performed research and 380 analysed data. All authors participated in the interpretation of results and the writing and 381 editing process.

382 Acknowledgments: This study was supported by funding from the Swiss Federal Institute 383 of Aquatic Science and Technology (Eawag) and the World Food System Center at ETH Zürich, 384 Switzerland. W.L. acknowledges the support received from the Early Postdoctoral Mobility 385 Fellowship awarded by Swiss National Science Foundation (P2EZP2_175096). C.F. was 386 supported by European Research Council Synergy grant ERC-2013-SynG-610028 Imbalance-P. C.M. acknowledges financial support from the MACMIT project (01LN1317A) funded 388 through the German Federal Ministry of Education and Research (BMBF).

389 Competing interests: The authors declare that they have no competing financial interests.

\section{References}

391 1. Bodirsky, B. L.; Popp, A.; Lotze-Campen, H.; Dietrich, J. P.; Rolinski, S.; Weindl, I.; 392 Schmitz, C.; Muller, C.; Bonsch, M.; Humpenoder, F.; Biewald, A.; Stevanovic, M., Reactive 393 nitrogen requirements to feed the world in 2050 and potential to mitigate nitrogen pollution.

394 Nat. Commun. 2014, 5, 3858.

395 2. Bodirsky, B. L.; Rolinski, S.; Biewald, A.; Weindl, I.; Popp, A.; Lotze-Campen, H., 396 Global food demand scenarios for the 21st century. PLoS One 2015, 10, (11), e0139201. 

Impacts of increased bioenergy demand on global food markets: an AgMIP economic model intercomparison. Agr. Econ. 2014, 45, (1), 103-116. intensification of agriculture. Proc. Natl. Acad. Sci. U.S.A. 2011, 108, (50), 20260-20264.

5. Matson, P. A.; Parton, W. J.; Power, A. G.; Swift, M. J., Agricultural intensification and ecosystem properties. Science 1997, 277, (5325), 504-509.

6. Deng, J. S.; Qiu, L. F.; Wang, K.; Yang, H.; Shi, Y. A. Y., An integrated analysis of urbanization-triggered cropland loss trajectory and implications for sustainable land management. Cities 2011, 28, (2), 127-137.

7. Lambin, E. F.; Meyfroidt, P., Global land use change, economic globalization, and the looming land scarcity. Proc. Natl. Acad. Sci. U.S.A. 2011, 108, (9), 3465-3472. 

Kucharik, C. J.; Monfreda, C.; Patz, J. A.; Prentice, I. C.; Ramankutty, N.; Snyder, P. K., 420 Global consequences of land use. Science 2005, 309, (5734), 570-574.

421 11. Godfray, H. C. J.; Garnett, T., Food security and sustainable intensification. Phil. Trans. R. Soc. B 2014, 369, (1639), 20120273.

12. Liu, W.; Yang, H.; Ciais, P.; Stamm, C.; Zhao, X.; Williams, J. R.; Abbaspour, K. C.;

Schulin, R., Integrative crop-soil-management modeling to assess global phosphorus losses from major crop cultivations. Global Biogeochem. Cycles 2018, 32, (7), 1074-1086. Acad. Sci. U.S.A. 2013, 110, (21), 8345-8348.

14. Bodirsky, B. L.; Muller, C., Robust relationship between yields and nitrogen inputs indicates three ways to reduce nitrogen pollution. Environ. Res. Lett. 2014, 9, (11), 111005. 15. Tilman, D.; Fargione, J.; Wolff, B.; D'Antonio, C.; Dobson, A.; Howarth, R.; Schindler, D.; Schlesinger, W. H.; Simberloff, D.; Swackhamer, D., Forecasting agriculturally driven 432 global environmental change. Science 2001, 292, (5515), 281-284.

436 17. Cui, Z. L.; Wang, G. L.; Yue, S. C.; Wu, L.; Zhang, W. F.; Zhang, F. S.; Chen, X. P., 437 Closing the N-use efficiency gap to achieve food and environmental security. Environ. Sci. 438 Technol. 2014, 48, (10), 5780-5787. 
18. Lassaletta, L.; Billen, G.; Grizzetti, B.; Anglade, J.; Garnier, J., 50 year trends in nitrogen use efficiency of world cropping systems: the relationship between yield and nitrogen input to cropland. Environ. Res. Lett. 2014, 9, (10), 105011.

19. Zhang, X.; Davidson, E. A.; Mauzerall, D. L.; Searchinger, T. D.; Dumas, P.; Shen, Y., Managing nitrogen for sustainable development. Nature 2015, 528, (7580), 51-59.

20. Clark, C. M.; Tilman, D., Loss of plant species after chronic low-level nitrogen deposition to prairie grasslands. Nature 2008, 451, (7179), 712-715.

21. Liu, J.; You, L.; Amini, M.; Obersteiner, M.; Herrero, M.; Zehnder, A. J.; Yang, H., A high-resolution assessment on global nitrogen flows in cropland. Proc. Natl. Acad. Sci. U.S.A. 2010, 107, (17), 8035-40.

22. Liu, X.; Zhang, Y.; Han, W.; Tang, A.; Shen, J.; Cui, Z.; Vitousek, P.; Erisman, J. W.; Goulding, K.; Christie, P.; Fangmeier, A.; Zhang, F., Enhanced nitrogen deposition over China. Nature 2013, 494, (7438), 459-62.

23. Schlesinger, W. H., On the fate of anthropogenic nitrogen. Proc. Natl. Acad. Sci. U.S.A. 2009, 106, (1), 203-208.

24. Steffen, W.; Richardson, K.; Rockstrom, J.; Cornell, S. E.; Fetzer, I.; Bennett, E. M.; Biggs, R.; Carpenter, S. R.; de Vries, W.; de Wit, C. A.; Folke, C.; Gerten, D.; Heinke, J.; Mace, G. M.; Persson, L. M.; Ramanathan, V.; Reyers, B.; Sorlin, S., Planetary boundaries: Guiding human development on a changing planet. Science 2015, 347, (6223), 1259855.

25. Babbin, A. R.; Ward, B. B., Controls on nitrogen loss processes in Chesapeake Bay sediments. Environ. Sci. Technol. 2013, 47, (9), 4189-96. 
26. Liu, W.; Yang, H.; Liu, J.; Azevedo, L. B.; Wang, X.; Xu, Z.; Abbaspour, K. C.; Schulin,

R., Global assessment of nitrogen losses and trade-offs with yields from major crop cultivations. Sci. Total Environ. 2016, 572, 526-537.

27. Liu, W.; Antonelli, M.; Liu, X.; Yang, H., Towards improvement of grey water footprint assessment: With an illustration for global maize cultivation. J. Cleaner Prod. 2017, 147, 1-9. 28. Cui, Z. L.; Yue, S. C.; Wang, G. L.; Zhang, F. S.; Chen, X. P., In-season root-zone N management for mitigating greenhouse gas emission and reactive $\mathrm{N}$ losses in intensive wheat production. Environ. Sci. Technol. 2013, 47, (11), 6015-6022.

29. Garnett, T.; Appleby, M. C.; Balmford, A.; Bateman, I. J.; Benton, T. G.; Bloomer, P.; Burlingame, B.; Dawkins, M.; Dolan, L.; Fraser, D.; Herrero, M.; Hoffmann, I.; Smith, P.; Thornton, P. K.; Toulmin, C.; Vermeulen, S. J.; Godfray, H. C., Agriculture. Sustainable intensification in agriculture: premises and policies. Science 2013, 341, (6141), 33-4.

30. Pretty, J., Agricultural sustainability: concepts, principles and evidence. Phil. Trans. $R$. Soc. B 2008, 363, (1491), 447-465.

31. Iizumi, T.; Yokozawa, M.; Sakurai, G.; Travasso, M. I.; Romanernkov, V.; Oettli, P.; Newby, T.; Ishigooka, Y.; Furuya, J., Historical changes in global yields: major cereal and legume crops from 1982 to 2006. Global Ecol. Biogeogr. 2014, 23, (3), 346-357.

32. Ray, D. K.; Mueller, N. D.; West, P. C.; Foley, J. A., Yield trends are insufficient to double global crop production by 2050. PLoS One 2013, 8, (6), e66428.

33. Ray, D. K.; Ramankutty, N.; Mueller, N. D.; West, P. C.; Foley, J. A., Recent patterns of crop yield growth and stagnation. Nat. Commun. 2012, 3, 5989. 

sufficient to achieve food security in China? PLoS One 2015, 10, (2), e0116430.

35. Carberry, P. S.; Liang, W. L.; Twomlow, S.; Holzworth, D. P.; Dimes, J. P.; McClelland, T.; Huth, N. I.; Chen, F.; Hochman, Z.; Keating, B. A., Scope for improved eco-efficiency varies among diverse cropping systems. Proc. Natl. Acad. Sci. U.S.A. 2013, 110, (21), $8381-8386$.

36. Brauman, K. A.; Siebert, S.; Foley, J. A., Improvements in crop water productivity increase water sustainability and food security—a global analysis. Environ Res Lett 2013, 8, (2), 024030 .

37. Chen, X.; Cui, Z.; Fan, M.; Vitousek, P.; Zhao, M.; Ma, W.; Wang, Z.; Zhang, W.; Yan, X.; Yang, J.; Deng, X.; Gao, Q.; Zhang, Q.; Guo, S.; Ren, J.; Li, S.; Ye, Y.; Wang, Z.; Huang, J.; Tang, Q.; Sun, Y.; Peng, X.; Zhang, J.; He, M.; Zhu, Y.; Xue, J.; Wang, G.; Wu, L.; An, N.; Wu, L.; Ma, L.; Zhang, W.; Zhang, F., Producing more grain with lower environmental costs. Nature 2014, 514, (7523), 486-9.

38. Chen, X. P.; Cui, Z. L.; Vitousek, P. M.; Cassman, K. G.; Matson, P. A.; Bai, J. S.; Meng, for food security. Proc. Natl. Acad. Sci. U.S.A. 2011, 108, (16), 6399-6404.

39. Johnston, M.; Licker, R.; Foley, J.; Holloway, T.; Mueller, N. D.; Barford, C.; Kucharik, intensification. Environ. Res. Lett. 2011, 6, (3), 034028. 
A., Global biomass production potentials exceed expected future demand without the need for cropland expansion. Nat. Commun. 2015, 6, 8946.

41. Mueller, N. D.; West, P. C.; Gerber, J. S.; MacDonald, G. K.; Polasky, S.; Foley, J. A., A tradeoff frontier for global nitrogen use and cereal production. Environ Res Lett 2014, 9, (5), 054002.

42. Liu, W. F.; Yang, H.; Folberth, C.; Wang, X. Y.; Luo, Q. Y.; Schulin, R., Global investigation of impacts of PET methods on simulating crop-water relations for maize. Agr. Forest Meteorol. 2016, 221, 164-175.

43. Cai, X. M.; Rosegrant, M. W., Global water demand and supply projections part - 1. A modeling approach. Water Int. 2002, 27, (2), 159-169. phenomenon? Global assessment of water shortage over the last two millennia. Environ. Res. Lett. 2010, 5, (3), 034006.

45. Müller, C.; Elliott, J.; Chryssanthacopoulos, J.; Arneth, A.; Balkovic, J.; Ciais, P.; Deryng, D.; Folberth, C.; Glotter, M.; Hoek, S.; Iizumi, T.; Izaurralde, R. C.; Jones, C.; Khabarov, N.; Lawrence, P.; Liu, W.; Olin, S.; Pugh, T. A. M.; Ray, D.; Reddy, A.; Rosenzweig, C.; Ruane,

519 Global gridded crop model evaluation: benchmarking, skills, deficiencies and implications.

520 Geosci. Model Dev. 2017, 10, 1403-1422. 
524 Schmid, E.; Wang, X.; de Wit, A.; Wu, X., Spatial and temporal uncertainty of crop yield 525 aggregations. Eur. J. Agron. 2017, 88, 10-21.

47. Portmann, F. T.; Siebert, S.; Doll, P., MIRCA2000-Global monthly irrigated and rainfed crop areas around the year 2000: A new high-resolution data set for agricultural and hydrological modeling. Global Biogeochem. Cycles 2010, 24.

48. Sacks, W. J.; Deryng, D.; Foley, J. A.; Ramankutty, N., Crop planting dates: an analysis of global patterns. Global Ecol. Biogeogr. 2010, 19, (5), 607-620. Closing yield gaps through nutrient and water management. Nature 2012, 490, (7419), 254-257.

50. West, P. C.; Gerber, J. S.; Engstrom, P. M.; Mueller, N. D.; Brauman, K. A.; Carlson, K. M.; Cassidy, E. S.; Johnston, M.; MacDonald, G. K.; Ray, D. K.; Siebert, S., Leverage points for improving global food security and the environment. Science 2014, 345, (6194), 325-328. 51. Folberth, C.; Yang, H.; Gaiser, T.; Liu, J.; Wang, X.; Williams, J.; Schulin, R., Effects of ecological and conventional agricultural intensification practices on maize yields in sub-Saharan Africa under potential climate change. Environ. Res. Lett. 2014, 9, (4), 044004.

540 52. Balkovič, J.; van der Velde, M.; Skalský, R.; Xiong, W.; Folberth, C.; Khabarov, N.;

541 Smirnov, A.; Mueller, N. D.; Obersteiner, M., Global wheat production potentials and 542 management flexibility under the representative concentration pathways. Global Planet. 

resources conservation and nitrogen pollution reduction under global food trade and agricultural intensification. Sci. Total Environ. 2018, 633, 1591-1601.

54. Williams, J. R., The EPIC model. In Computer Models of Watershed hydrology, Singh, V.

Folberth, C.; Glotter, M.; Khabarov, N.; Neumann, K.; Piontek, F.; Pugh, T. A. M.; Schmid, E.; $111,(9), 3268-3273$. agronomic performance, pollution, trade, and dietary demand. Environ. Res. Lett. 2016, 11,

57. Mueller, N. D.; Lassaletta, L.; Runck, B. C.; Billen, G.; Garnier, J.; Gerber, J. S.,

Declining spatial efficiency of global cropland nitrogen allocation. Global Biogeochem. Cycles 2017, 31, (2), 245-257.

561 58. Mogollón, J. M.; Lassaletta, L.; Beusen, A. H. W.; van Grinsven, H. J. M.; Westhoek, H.;

562 Bouwman, A. F., Assessing future reactive nitrogen inputs into global croplands based on the 563 shared socioeconomic pathways. Environ. Res. Lett. 2018, 13, (4). 
Yield gap analysis with local to global relevance-A review. Field Crop Res. 2013, 143, 4-17.

60. Peel, M. C.; Finlayson, B. L.; McMahon, T. A., Updated world map of the

567 Koppen-Geiger climate classification. Hydrol. Earth Syst. Sci. 2007, 11, (5), 1633-1644.

61. Balkovič, J.; van der Velde, M.; Schmid, E.; Skalský, R.; Khabarov, N.; Obersteiner, M.;

569 Sturmer, B.; Xiong, W., Pan-European crop modelling with EPIC: Implementation, up-scaling 570 and regional crop yield validation. Agr. Syst. 2013, 120, 61-75.

571 62. Khush, G. S., Green revolution: the way forward. Nat. Rev. Genet. 2001, 2, (10), $572 \quad 815-822$.

573 63. Challinor, A. J.; Parkes, B.; Ramirez-Villegas, J., Crop yield response to climate change 574 varies with cropping intensity. Global Change Biol. 2015, 21, (4), 1679-1688.

575 64. van Grinsven, H. J. M.; Erisman, J. W.; de Vries, W.; Westhoek, H., Potential of 576 extensification of European agriculture for a more sustainable food system, focusing on 577 nitrogen. Environ. Res. Lett. 2015, 10, (2), 025002.

578 65. Ebert, A., Potential of underutilized traditional vegetables and legume crops to contribute 579 to food and nutritional security, income and more sustainable production systems. 580 Sustainability 2014, 6, (1), 319-335.

581 66. Wang, N.; Wolf, J.; Zhang, F., Towards sustainable intensification of apple production in 582 China - Yield gaps and nutrient use efficiency in apple farming systems. Journal of 583 Integrative Agriculture 2016, 15, (4), 716-725.

584 67. Sutton, M., A.; Bleeker, A.; Howard, C. M.; Bekunda, M.; Grizzetti, B.; de Vries, W.; van 585 Grinsven, H. J., M.; Abrol, Y. P.; Adhya, T. K.; Billen, G.; Davidson, E. A.; Datta, A.; Diaz, R.; 

and energy with less pollution. Centre for Ecology and Hydrology (CEH): 2013.

68. Liu, W.; Antonelli, M.; Kummu, M.; Zhao, X.; Wu, P.; Liu, J.; Zhuo, L.; Yang, H., 590 Savings and losses of global water resources in food-related virtual water trade. WIREs Water

591

2018, e1320.

69. Oki, T.; Kanae, S., Global hydrological cycles and world water resources. Science 2006, 313, (5790), 1068-1072.

70. Elliott, J.; Deryng, D.; Mueller, C.; Frieler, K.; Konzmann, M.; Gerten, D.; Glotter, M.; Florke, M.; Wada, Y.; Best, N.; Eisner, S.; Fekete, B. M.; Folberth, C.; Foster, I.; Gosling, S. N.; Haddeland, I.; Khabarov, N.; Ludwig, F.; Masaki, Y.; Olin, S.; Rosenzweig, C.; Ruane, A. C.; Satoh, Y.; Schmid, E.; Stacke, T.; Tang, Q. H.; Wisser, D., Constraints and potentials of future irrigation water availability on agricultural production under climate change. Proc. Natl. Acad. Sci. U.S.A. 2014, 111, (9), 3239-3244.

71. Jagermeyr, J.; Gerten, D.; Heinke, J.; Schaphoff, S.; Kummu, M.; Lucht, W., Water savings potentials of irrigation systems: global simulation of processes and linkages. Hydrol. Earth Syst. Sci. 2015, 19, (7), 3073-3091.

72. Jagermeyr, J.; Gerten, D.; Schaphoff, S.; Heinke, J.; Lucht, W.; Rockstrom, J., Integrated crop water management might sustainably halve the global food gap. Environ. Res. Lett. 2016, $11,(2), 025002$.

73. Zhang, X., BIOGEOCHEMISTRY A plan for efficient use of nitrogen fertilizers. Nature 
74. Li, Z.; Xu, M.; Zhang, H.; Zhang, W.; Gao, J., Grain yield trends of different food crops

609 under long-term fertilization in China. Scientia Agricultura Sinica 2009, 42, (7), 2407-2414.

610 75. Stewart, W. M.; Dibb, D. W.; Johnston, A. E.; Smyth, T. J., The contribution of 611 commercial fertilizer nutrients to food production. Agron. J. 2005, 97, (1), 1-6. 76. Elliott, J.; Müller, C.; Deryng, D.; Chryssanthacopoulos, J.; Boote, K.; Büchner, M.;

613 Foster, I.; Glotter, M.; Heinke, J.; Iizumi, T., The Global Gridded Crop Model 614 Intercomparison: data and modeling protocols for Phase 1 (v1. 0). Geosci. Model Dev. 2015, 8, 615 (2), 261-277.

616 77. Sinha, E.; Michalak, A. M.; Balaji, V., Eutrophication will increase during the 21st 617 century as a result of precipitation changes. Science 2017, 357, (6349), 405-408.

618 78. Pugh, T. A.; Muller, C.; Elliott, J.; Deryng, D.; Folberth, C.; Olin, S.; Schmid, E.; Arneth, 619 A., Climate analogues suggest limited potential for intensification of production on current 620 croplands under climate change. Nat. Commun. 2016, 7, 12608.

621 79. Ray, D. K.; Gerber, J. S.; MacDonald, G. K.; West, P. C., Climate variation explains a 622 third of global crop yield variability. Nat. Commun. 2015, 6, 5989. 

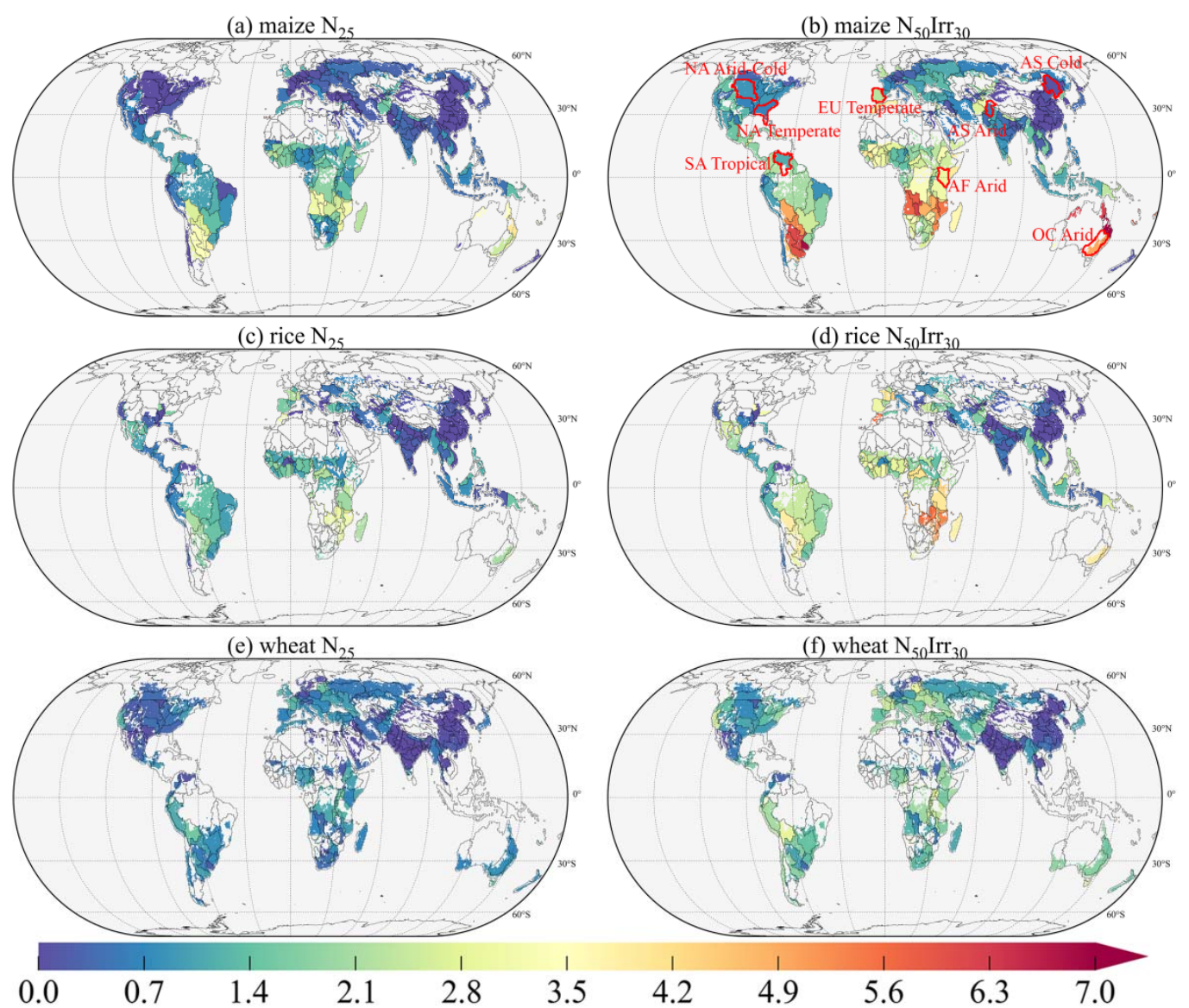

Figure 1. Differences in crops yields [t per ha] between $\mathrm{N}_{25}$ and baseline (a, c, e), as well as between $\mathrm{N}_{50} \operatorname{Irr}_{30}$ and baseline ( $\left.\mathrm{b}, \mathrm{d}, \mathrm{f}\right)$. Note: eight continent-climate regions in panel $\mathrm{b}$ are used to detail the responses of yields and nitrogen emissions to nitrogen inputs under irrigated and rainfed cultivations. Maps of different food production units were obtained from Kummu et al. ${ }^{44}$ AF: Africa, AS: Asia, EU: Europe, NA: North America, OC: Oceania, SA: South America. 

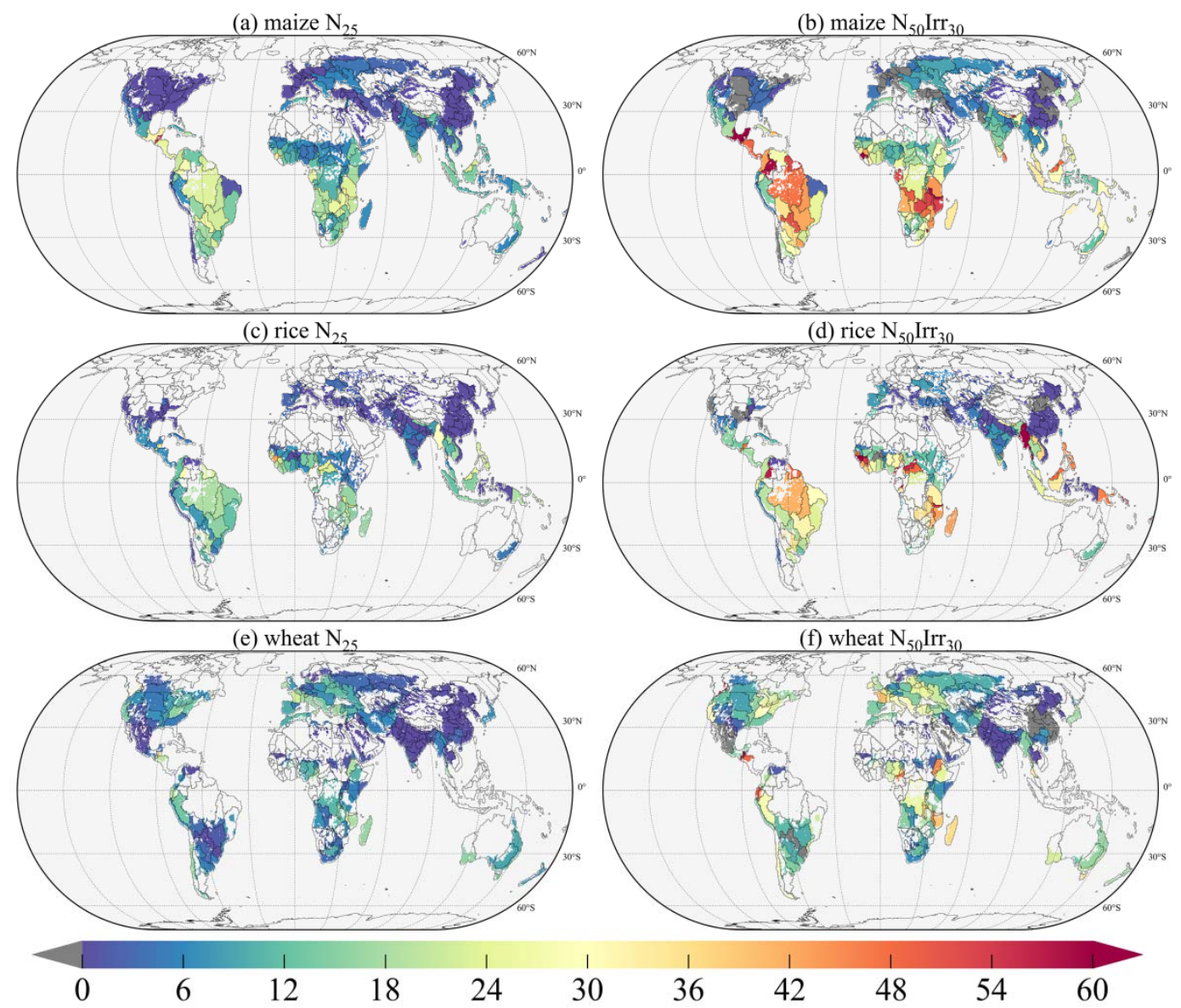

Figure 2. Differences in nitrogen $(\mathrm{N})$ emissions [ $\mathrm{kg} \mathrm{N}$ per ha] between $\mathrm{N}_{25}$ and baseline (a, c, e), as well as between $\mathrm{N}_{50} \mathrm{Irr}_{30}$ and baseline (b, d, f). Maps of different food production units were obtained from Kummu et al. ${ }^{44}$ 

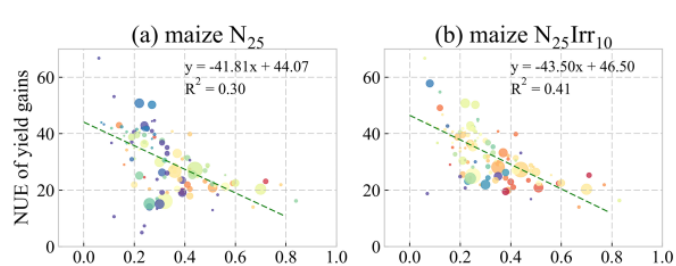

(c) maize $\mathrm{N}_{50} \operatorname{Irr}_{30}$
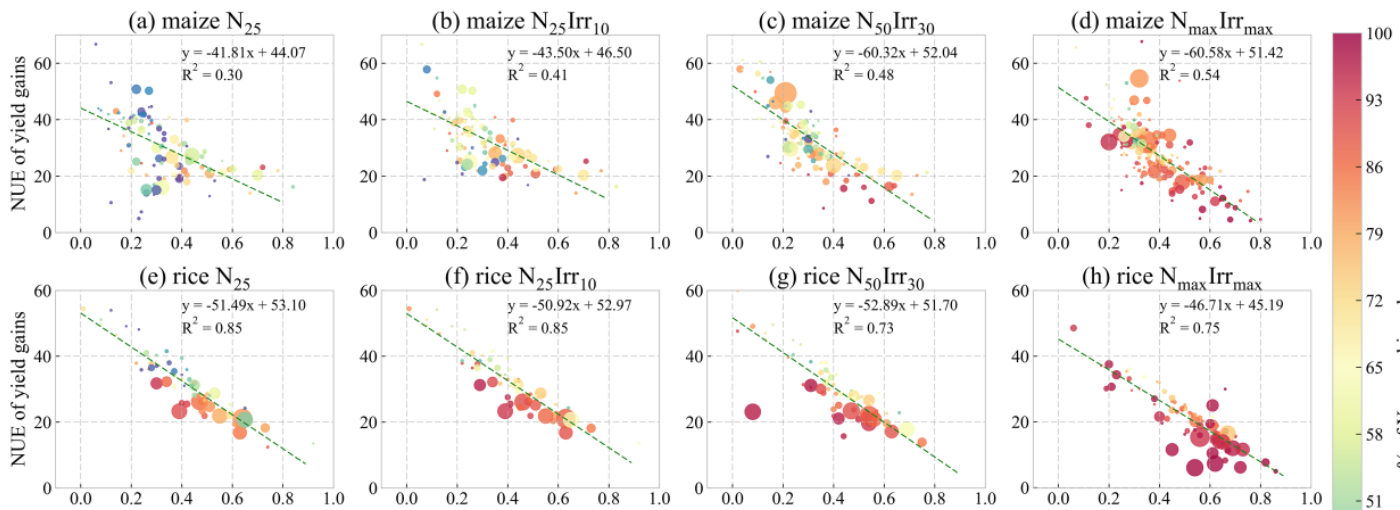

(f) rice $\mathrm{N}_{25} \operatorname{Irr}_{10}$

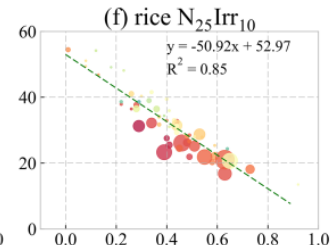

(g) rice $\mathrm{N}_{50} \mathrm{Irr}_{30}$

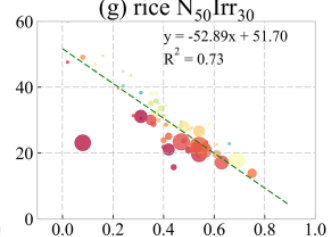

(h) rice $\mathrm{N}_{\text {max }} \mathrm{Irr}_{\mathrm{m}}$

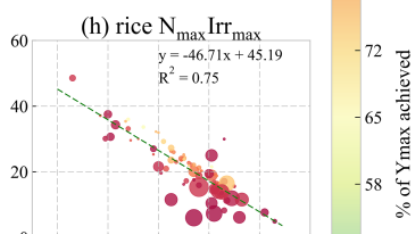

(i) wheat $\mathrm{N}_{25}$

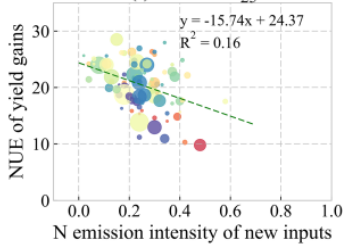

(j) wheat $\mathrm{N}_{25} \operatorname{Irr}_{10}$

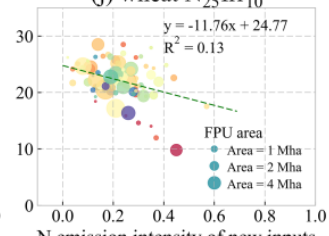

(k) wheat $\mathrm{N}_{50} \operatorname{Irr}_{30}$
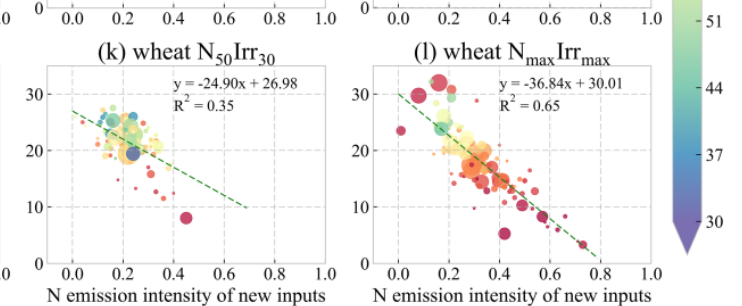

Figure 3. Relationships between nitrogen $(\mathrm{N})$ use efficiency (NUE) of yield gains [kg grain per kg N] and $\mathrm{N}$ emission intensity of new inputs [-] under different intensification scenarios at the food production units (FPUs) level. Ymax is estimated yields by PEPIC under the $\mathrm{N}_{\max } \mathrm{Irr}_{\max }$ scenario. The FPUs with the smallest areas (for a total of $2 \%$ of global total cropland areas of each crop) are not shown. Size represents cropland area for each FPU. Colors represent the fractions to which Ymax have been achieved. For a given intensification scenario, the colors show the situation of its previous scenario with an intensification order of baseline, $\mathrm{N}_{25}, \mathrm{~N}_{25} \operatorname{Irr}_{10}, \mathrm{~N}_{50} \operatorname{Irr}_{30}$ and $\mathrm{N}_{\max } \operatorname{Irr}_{\max }$ scenarios. That is to say, for instance, colors in $\mathrm{N}_{25}$ give the achieved Ymax fractions of the baseline scenario. Equations represent the linear relationship between NUE of yield gains and $\mathrm{N}$ emission intensity of new inputs (points with negative $\mathrm{N}$ emission intensity of new inputs are not included for regression analysis). $\mathrm{R}^{2}$ is the coefficient of determination of equation. 
(a) maize w/o $80 \%$ Ymax achieved

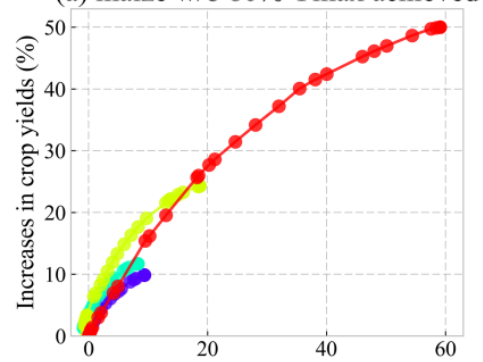

(c) rice w/o $80 \%$ Ymax achieved

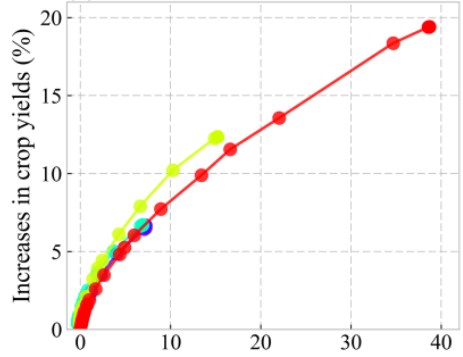

(e) wheat w/o $80 \%$ Ymax achieved

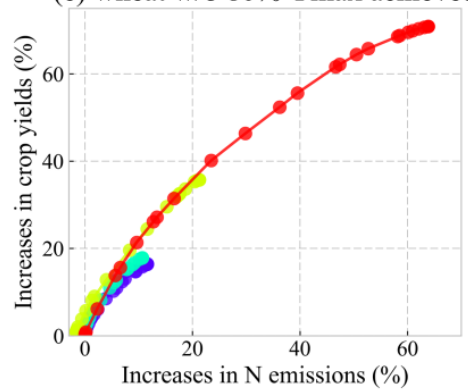

(b) maize w/ 80\% Ymax achieved

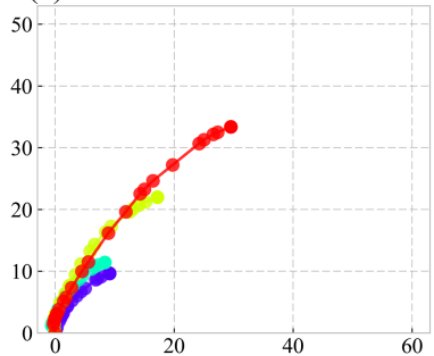

(d) rice $w / 80 \%$ Ymax achieved

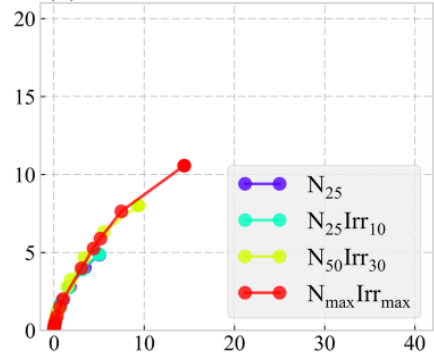

(f) wheat w/ 80\% Ymax achieved

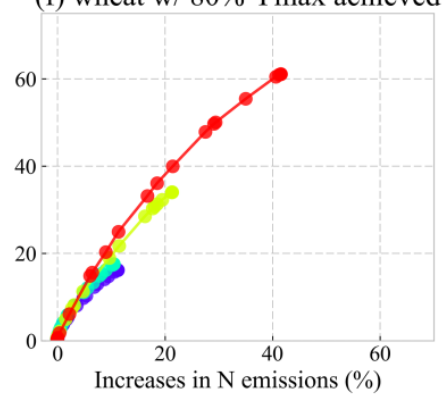

Figure 4. Percentage increases in global average crop yields and nitrogen $(\mathrm{N})$ emissions under different intensification scenarios without (w/o) considering $80 \%$ of maximum yields (Ymax) achieved (a, c, e) and with (w/) considering $80 \%$ of Ymax achieved (b, d, f). Considering $80 \%$ of Ymax achieved means that the food production units (FPUs) with $80 \%$ of Ymax achieved under a given intensification scenario adopt the first scenario of baseline, $\mathrm{N}_{25}, \mathrm{~N}_{25} \operatorname{Irr}_{10}$ and $\mathrm{N}_{50} \mathrm{Irr}_{30}$, which has already achieved $80 \%$ of Ymax. Points in each curve are derived by intensifying FPUs one-by-one with an ascending order of $\mathrm{N}$ emission intensity of new inputs and then a descending order of $\mathrm{N}$ use efficiency of yield gains on the basis of Fig. 3. For better visualization, every 10 points between the first and last points are plotted for each curve. Note: lines for $\mathrm{N}_{\max } \operatorname{Irr}_{\max }$ are not always highest because different sorting sequences are used for different scenarios. 
(a) AF Arid

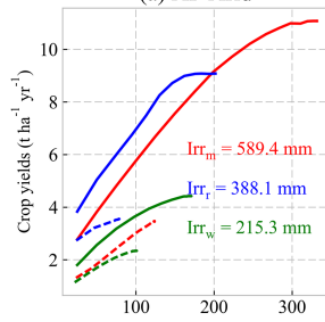

(c) OC Arid

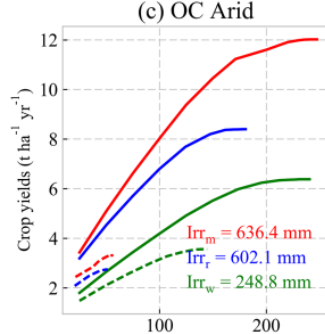

(e) AS Arid

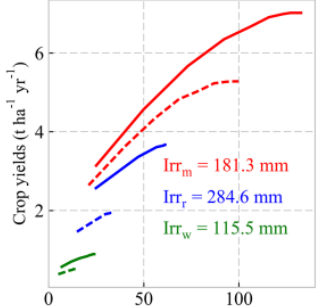

(g) NA Arid-Cold

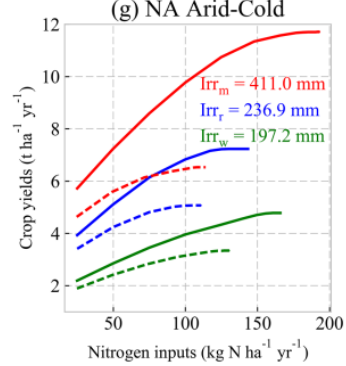

(b) EU Temperate

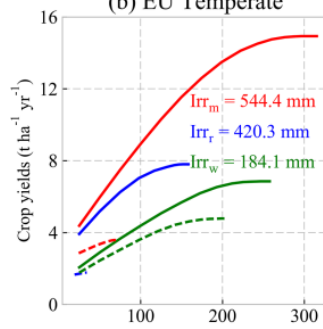

(d) SA Tropical

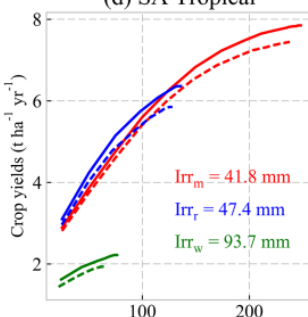

(f) AS Cold

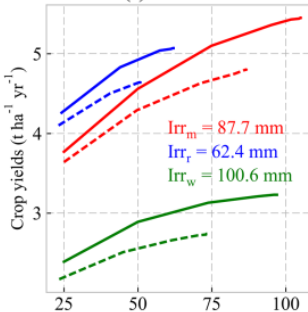

(h) NA Temperate

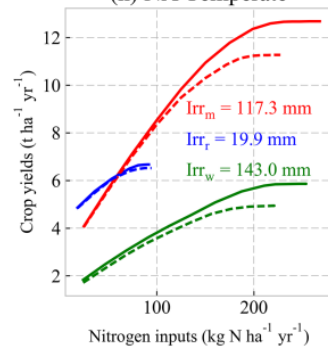

(i) AF Arid

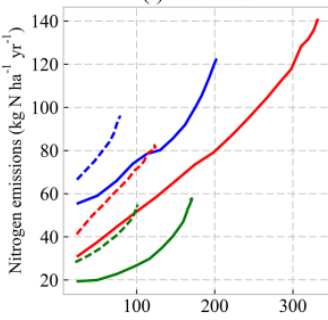

(k) OC Arid

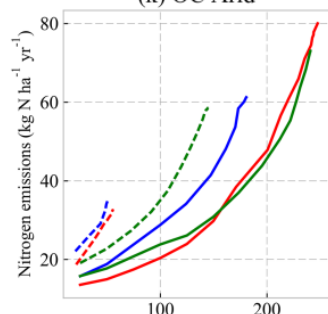

(m) AS Arid

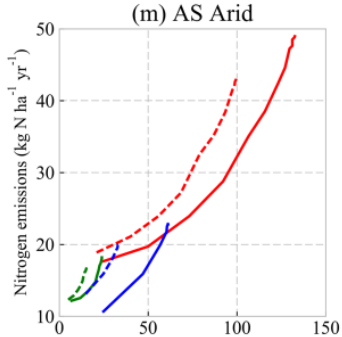

(o) NA Arid-Cold

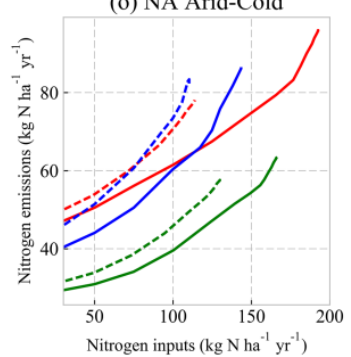

(j) EU Temperate

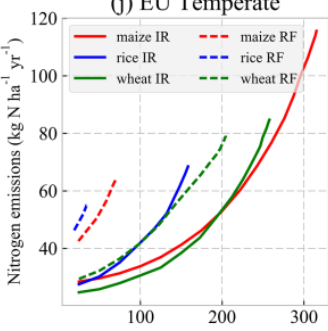

(1) SA Tropical

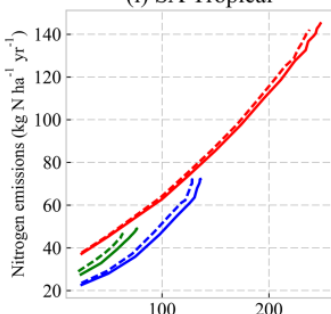

(n) AS Cold

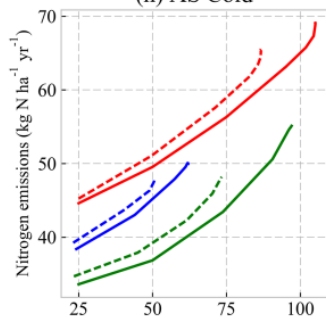

(p) NA Temperate

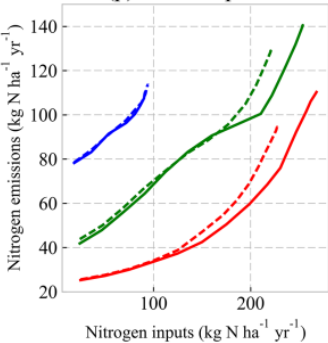

Figure 5. Response curves of crop yields (a-h) and nitrogen (N) emissions (i-p) to $\mathrm{N}$ inputs $\left(\mathrm{N}_{\text {in }}\right)$ under irrigated (IR, solid lines) and rainfed (RF, dashed lines) cultivations in different continental-climate regions. $\operatorname{Irr}_{\mathrm{m}}$ : irrigation water requirements of maize; $\operatorname{Irr}_{\mathrm{r}}$ : irrigation water requirements of rice; $\operatorname{Irr}_{\mathrm{w}}$ : irrigation water requirements of wheat. A map of the continental-climate regions can be found in Fig. 1b. AF: Africa, AS: Asia, EU: Europe, NA: North America, OC: Oceania, SA: South America. The response curves are derived from simulations with automatic $\mathrm{N}$ fertilization by setting different $\mathrm{N}_{\text {in }}$ caps: $25,50, \ldots 400,450$, 500, and $1000 \mathrm{~kg} \mathrm{~N} \mathrm{ha}^{-1} \mathrm{yr}^{-1}$. Actual $\mathrm{N}_{\text {in }}$ is lower than $\mathrm{N}_{\text {in }}$ cap when a high-level cap is used. Rainfed cultivation has lower maximum $\mathrm{N}_{\text {in }}$ than irrigated cultivation. 
Table 1. Description of intensification scenarios in terms of increasing nitrogen $(\mathrm{N})$ inputs and irrigation (Irr) areas.

\begin{tabular}{|c|c|c|}
\hline Scenario & $\mathrm{N}$ inputs & $\begin{array}{l}\text { Irrigation } \\
\text { areas }\end{array}$ \\
\hline baseline & $\mathrm{N}_{\text {in-base }}$ & $\mathrm{A}_{\mathrm{ir}}$ \\
\hline $\mathrm{N}_{25}$ & $\mathrm{~N}_{\text {in-base }}+0.25 \times \Delta \mathrm{N}_{\text {in-max }}$ & $\mathrm{A}_{\mathrm{ir}}$ \\
\hline $\mathrm{N}_{25} \operatorname{Irr}_{10}$ & $\mathrm{~N}_{\text {in-base }}+0.25 \times \Delta \mathrm{N}_{\text {in-max }}$ & $\mathrm{A}_{\mathrm{ir}}+0.10 \times \mathrm{A}_{\mathrm{rf}}$ \\
\hline $\mathrm{N}_{50} \mathrm{Irr}_{30}$ & $\mathrm{~N}_{\text {in-base }}+0.50 \times \Delta \mathrm{N}_{\mathrm{in}-\max }$ & $\mathrm{A}_{\mathrm{ir}}+0.30 \times \mathrm{A}_{\mathrm{rf}}$ \\
\hline $\mathrm{N}_{\max } \operatorname{Irr}_{\max }$ & $\mathrm{N}_{\text {in-max }}$ & Full irrigation \\
\hline
\end{tabular}

Table 2. Global average irrigation water (Irr) [mm], nitrogen inputs $\left(\mathrm{N}_{\text {in }}\right)[\mathrm{kg} \mathrm{N}$ per ha], crop yields (Y) [t per ha], and nitrogen emissions $\left(\mathrm{N}_{\mathrm{e}}\right)$ [kg N per ha] under baseline and different intensification scenarios by intensifying all croplands.

\begin{tabular}{|c|c|c|c|c|c|c|c|c|c|c|c|c|}
\hline & \multicolumn{4}{|l|}{ maize } & \multicolumn{4}{|l|}{ rice } & \multicolumn{4}{|l|}{ wheat } \\
\hline & Irr & $\mathrm{N}_{\mathrm{in}}$ & $\mathrm{Y}$ & $\mathrm{N}_{\mathrm{e}}$ & Irr & $\mathrm{N}_{\text {in }}$ & $\mathrm{Y}$ & $\mathrm{N}_{\mathrm{e}}$ & Irr & $\mathrm{N}_{\text {in }}$ & $\mathrm{Y}$ & $\mathrm{N}_{\mathrm{e}}$ \\
\hline baseline & 50.2 & 93.2 & 5.5 & 68.3 & 41.3 & 86.8 & 4.5 & 74.2 & 44.7 & 70.7 & 2.7 & 43.4 \\
\hline $\mathrm{N}_{25}$ & 50.2 & 111.0 & 6.0 & 74.7 & 41.3 & 97.5 & 4.8 & 79.5 & 44.7 & 92.1 & 3.1 & 48.5 \\
\hline $\mathrm{N}_{25} \operatorname{Irr}_{10}$ & 62.0 & 111.5 & 6.1 & 73.9 & 42.1 & 97.5 & 4.8 & 79.3 & 55.4 & 92.3 & 3.2 & 48.0 \\
\hline $\mathrm{N}_{50} \mathrm{Irr}_{30}$ & 86.8 & 132.8 & 6.8 & 81.0 & 43.9 & 108.9 & 5.1 & 85.4 & 78.0 & 114.2 & 3.6 & 52.7 \\
\hline $\mathrm{N}_{\max } \operatorname{Irr}_{\max }$ & 173.0 & 193.0 & 8.2 & 108.6 & 50.1 & 136.0 & 5.4 & 102.9 & 156.7 & 168.2 & 4.6 & 71.1 \\
\hline
\end{tabular}

Table 3. Global average irrigation water (Irr) [mm], nitrogen inputs $\left(\mathrm{N}_{\mathrm{in}}\right)[\mathrm{kg} \mathrm{N}$ per ha], crop yields $(\mathrm{Y})$ [t per ha], and nitrogen emissions $\left(\mathrm{N}_{\mathrm{e}}\right)[\mathrm{kg} \mathrm{N}$ per ha] under different intensification scenarios by avoiding further intensifying croplands with $80 \%$ of maximum $\mathrm{Y}$ achieved.

\begin{tabular}{|c|c|c|c|c|c|c|c|c|c|c|c|c|}
\hline & \multicolumn{4}{|c|}{ maize } & \multicolumn{4}{|c|}{ rice } & \multicolumn{4}{|c|}{ wheat } \\
\hline & Irr & $\mathrm{N}_{\text {in }}$ & $\mathrm{Y}$ & $\mathrm{N}_{\mathrm{e}}$ & Irr & $\mathrm{N}_{\text {in }}$ & Y & $\mathrm{N}_{\mathrm{e}}$ & Irr & $\mathrm{N}_{\text {in }}$ & $\mathrm{Y}$ & $\mathrm{N}_{\mathrm{e}}$ \\
\hline $\mathrm{N}_{25}$ & 50.2 & 110.6 & 6.0 & 74.5 & 41.3 & 94.4 & 4.7 & 77.9 & 44.7 & 91.7 & 3.1 & 48.3 \\
\hline $\mathrm{N}_{25} \operatorname{Irr}_{10}$ & 61.5 & 111.1 & 6.1 & 73.9 & 41.8 & 94.4 & 4.7 & 77.9 & 54.9 & 91.8 & 3.2 & 48.0 \\
\hline $\mathrm{N}_{50} \operatorname{Irr}_{30}$ & 79.7 & 129.0 & 6.7 & 80.0 & 42.7 & 100.2 & 4.9 & 81.1 & 75.2 & 112.0 & 3.6 & 52.7 \\
\hline $\mathrm{N}_{\max } \mathrm{Irr}_{\max }$ & 117.6 & 150.7 & 7.3 & 88.4 & 44.8 & 106.8 & 5.0 & 84.9 & 131.0 & 146.5 & 4.3 & 61.5 \\
\hline
\end{tabular}

